\title{
Training Specialists in Finances and Economics Using Virtual Educational Space
}

\author{
Liudmila Kutepova \\ Kazan branch \\ Volga State University of Water Transport \\ Kazan, Russia \\ masa_m@bk.ru \\ Nuraniya Harisova \\ Kazan branch \\ Volga State University of Water Transport \\ Kazan, Russia \\ nur.har@mail.ru \\ Ilsiya Timerbulatova \\ Kazan branch \\ Volga State University of Water Transport \\ Kazan, Russia \\ it70@mail.ru
}

\author{
Ilyas Salakhov \\ Kazan branch \\ Volga State University of Water Transport \\ Kazan, Russia \\ ilyas.salakhov.1@mail.ru \\ Margarita Ignatyeva \\ Kazan branch \\ Volga State University of Water Transport \\ Kazan, Russia \\ margoig62@gmail.com \\ Roman Smirnov \\ Kazan branch \\ Volga State University of Water Transport \\ Kazan, Russia \\ roman-kazan2008@yandex.ru
}

\begin{abstract}
In this article we defined major opportunities of virtual educational space in training of specialists in financial and economic area, we also analyzed information technology facilities that are used in the process of training.

The objective of this article is to analyze the opportunities of virtual educational space in training of specialists in financial and economic area and to determine the features of it.

We have defined the peculiarities of training of future financial and economic specialists. They consist of two types: a person - a sign system and a person - a person. It lays down the core professional competencies of future economist, personal and professional qualities.

We have figured out that virtual educational space is able to provide all the necessary personal and professional competencies of future specialists in financial and economic area. It has been shown that the use of information technology in economic education has some methodological features that are determined by the structure of the multi-stage curriculum.

It has been found that information technology facilities are used both in theory and practice in the process of training. Key information technologies used are computer learning systems, multimedia training courses, business computer games, video conferences.
\end{abstract}

Keywords: economist, training, information technology, expert systems, virtual educational space

\section{INTRODUCTION}

The rapid development of computers, the transition of society to the information era have led to creation of new surroundings - cyberspace.

Cyberspace is becoming a familiar environment for professional activity, education, communication and relaxation, forming a new system of values, goals and needs of the individual.

Problems related to the use of information and communication technologies in education, which are aimed at fulfilling psychological and pedagogical objectives of education, upbringing, formation and development of virtual educational space become especially relevant in these conditions.

A considerable attention to the creation and development of a unified information and educational environment is given at the state level.

The main activities for the informatization of education are the formation and implementation of an information, educational environment in the system of higher and postgraduate education, the creation of an information system to support educational process. 
research. P.Boattke, D.Prichitko, P.Heine and others considered the problems of new economic thinking.

A.Amend, N.Ryabinina, V.Rozov and others addressed issues about readiness of professional for independent economic activity in the current context.

N.Balovsyak, E.Benkovich, O.Kamensky, T.Koval, T.Liminiva, T.Poyasok, S.Radetskaya, N.Sprozhetskaya, N.Tverezovskaya conducted studies on computerization of economic education, on development of information competence of future professionals, techniques of certain economic disciplines study with the use of computer resources.

However, it is still necessary to study in depth particularities of professionals training in conditions of virtual educational space, that trains highly qualified professionals that are capable to think systematically, to process large amount of information and identify the key moments in it, to adapt to advances of information and communication technology rapidly.

A rapid advance of information and communication technologies, their widespread deployment in all areas of social life have led to new fields of knowledge and high technology, to creation of a new automatic equipment, to economic systems developing, improvement of management of social-economic and technological processes.

Such features of social development have led to requirements of continuous improvement and acquisition of new knowledge and skills in the world today. Only lifelong learning can satisfy these requirements and education system has to provide such opportunities [4-7].

The modernization of the education system must lead to increase of its access which is to ensure equal access to quality education for everyone, broadening of the range of educational services.

Exactly the creation of virtual educational space allows complete all the tasks.

Virtual educational space is a system of educational components that consists of a set of integrated information and pedagogical technologies.

They are implemented in the process of interaction of subjects with virtual educational resources and it is characterized by an adequate representation of dialectic interrelated fields of human activity (intellectual, emotional, cultural, social) and their adaptation to student's subjectivity [8].

Analysis of research on the problems of creation and use of information educational space made it possible to determine the main possibilities of virtual education [4, 8-13]:

- the possibility of exercising communication of educational process subjects;

- the possibility of optimization of students' activity through their interactive engagement with distributed electronic educational resources; 
The training of professionals under virtual educational

- the possibility to access information resources at any time and in any place;

- the possibility to provide unlimited amount of information from any branch of knowledge, the existence in Internet of a large number of special training courses from different disciplines that is steadily growing;

- the possibility of the use of virtual reality technology that allows for modelling the area of professional activity, for imitating of various situations for shaping of skills;

- psychological-pedagogical opportunities (activities in information space contribute to the development of theoretical, figurative, intuitive, creative thinking; to building skills of analysis, synthesis, induction, deduction, abstraction).

The opportunities of virtual learning space mentioned above have a high potential for training of professionals in financial and economic area.

We take note of the features of training of future professionals in financial and economic areas.

An economist faces information (sign systems), other people that participate in economic relations, so an economist as a profession refers to the types "person-sign system" and "person-person".

Thus, major profession competencies in this area are as follows: encyclopedic knowledge, a high level of information competence, understanding of economics and finance, systems thinking, simultaneous using of several systems, the ability to respond to a general situation rapidly and anticipate its development, tolerance, etc. [14-17]

A wide application and a rapid increase of information technologies significance in all financial and economic institutions of the state are changing the requirements of training of a modern-day economist, taking into account the need of building an ability to use information technologies not only for professional purposes, but also for organizing effective learning experiences [17].

With the development of high technology and knowledgebased industries in the global economy there is a need for highly skilled professionals in economic and finance areas, who have certain personal and professional qualities. Among them the employers single out the following in particular [18]:

- the overall level of development and basic knowledge of a professional;

- the ability to think systematically and to process a great deal of information and highlight important things;

- the ability to use received knowledge in practice and study all the time;

- focus on career, sense of purpose, adequacy of selfassessment as a professional. space provides the formation of mentioned competencies, personal and professional qualities.

The possibility of virtual educational space to exercise communication of educational process subjects allows acquire skills to contact people, be flexible in communication, listen to, convincingly and clearly to speak their views, be tolerant of others and the like. That is to say, the described possibility let form competencies that are necessary for occupation like "person-person".

The possibility of optimization of students' work through their interactive independent engagement with distributed electronic educational resources encourages self-improvement, self-development, cognitive skills training and students' own activity.

The opportunity to provide unlimited amount of information allows obtain necessary professional knowledge. Using information resources of virtual educational space (computer-based training program, distance-learning courses, electronic textbooks, background information, educational videos, training materials, etc.) future specialists not only acquire the necessary knowledge, but also receive skills to process a great deal of information and highlight important things, skills of analysis, synthesis, induction, deduction, abstraction.

All this contributes to building of competencies that are necessary for profession of type "person-sign system": encyclopedic knowledge, a high level of information competence, understanding of economics and finance, systems thinking, simultaneous using of several systems, the ability to respond to a general situation rapidly and anticipate its development, tolerance, etc.

The possibility of using the technology of virtual reality, in which high realistic modelling of a multi-component space of professional ability supports a dynamic interactive engagement with a student, create the effect of immersion into a modelled space of professional activities.

The use of an interactive model of stock exchange, business models of organizations, simulation models of regional socio-economic systems, budgeting processes of industrial enterprises, project development of enterprise modernization allow simulate future professional student activity.

Thanks to a number of experiments with computer models of economic targets, computer-assisted research, meeting the challenges with the use of necessary software product, applications from various economic disciplines, development of business-plans, implementation of professional creative challenges, students improve themselves, obtain the skills to use received knowledge in practice, to analyze and synthesize information, draw conclusions, to assess a general situation rapidly and anticipate its development which leads to professional competence.

It should be noted, that effective solution of professional tasks in the reality of economic situations requires a number of operations and a person carries out more effectively some of 
TABLE I. QUANTITATIVE DATA OF THE EXPERIMENT

them, but some of them a computer carries out faster and better.

The combined advantages of a person like a manager and information technology, while compensating for disadvantages, is translated into information expert systems, that don't replace a creative approach of a professional but assist to analyze a large volume of data, to consider expert assessments, to create a set of possible solutions, to analyze their compatibility with various criteria, to anticipate the consequences of the decisions taken, to obtain the rationale of the chosen solution.

Expert system is a comprehensive software program that is able to reproduce thinking of an expert when analyzing and solving problems [19-20]. The systems for testing of knowledge, of decision-making process, program training and others act as varieties.

The integration of these systems in the process of studying creates educational expert system that links skills and knowledge, that are formed, implemented and improved in various kinds of professional activity.

The results orientation distinguishes this integration, namely: self-improvement and professionalization that lead to professional competence.

For the intensification of the training of future professionals it is feasible to use information expert systems (integrated computer programs), that provide feedback rapidly, computer visualization of educational information, archiving of large amount of data with an easy access to database, automation of processes for computational, information and retrieval activity, processing of the results of experiments, the automation of management of training activities and monitoring of results.

Experimental work on training professionals organized around higher education institution allow to describe criteria and indications for levels of students ' initial economic competencies; determine the baseline level students' economic competencies in experimental and control groups; introduce the elements of virtual educational program into students' training program in experimental group; ensure that the students of experimental group will achieve the level of economic competencies

According to the results of a forming stage, there was a strong increase of economic competencies level in the experimental group. Table 1 provides summary data. The reliability of differences of characteristics in experimental and control groups was statistically determined on the basis of the Kolmogorov-Smirnov criterion $(\mathrm{p}<0.05)$.

\begin{tabular}{|l|l|l|l|l|l|}
\hline \multirow{2}{*}{$\begin{array}{c}\text { Economic } \\
\text { competencies }\end{array}$} & \multirow{2}{*}{ Levels } & \multicolumn{3}{|c|}{ Number of students(\%) } \\
\cline { 3 - 6 } comperimental groups \\
\hline Competencies & low & 21.66 & 21.85 & 9.21 & 2.63 \\
"person- & middle & 71.97 & 57.77 & 78.29 & 14.47 \\
person" & high & 6.37 & 20.38 & 12.5 & 82.9 \\
\hline Competencies & low & 34.39 & 26.94 & 25.66 & 1.97 \\
"person-sign & middle & 65.61 & 68.6 & 71.71 & 61.18 \\
system" & high & 0 & 4.46 & 2.63 & 36.85 \\
\hline Professional & low & 64.33 & 43.95 & 63.82 & 5.92 \\
& middle & 35.37 & 56.05 & 36.18 & 67.76 \\
& high & 0 & 0 & 0 & 26.32 \\
\hline
\end{tabular}

\section{RESULTS AND DISCUSSION}

Based on analysis of research on the problems of creation and use of information educational space it was determined its main opportunities aimed at organizing of independent research activity, variability of content of training, the relationship between a student and an interactive environment; increase of the creativity of future professionals; analysis and planning of flow of information; efficient training of future professionals.

The features of training of future professionals in finance and economic areas have been determined that applies this occupation to the type "person-sign system", "person-person".

This determines the main professional competencies (encyclopedic knowledge, a high level of information competence, understanding of economics and finance, systems thinking, simultaneous using of several systems, the ability to respond to a general situation rapidly and anticipate its development, tolerance, etc.).

The study also found that virtual educational space is able to provide building of all necessary competencies, personal and professional characteristics of future specialists in economic and finance areas.

It was found that one of the priority areas of the use of information technology in the learning process of high economic school are expert systems (an integrated software program that in the process of work is able to reproduce thinking of an expert when analyzing and solving problems) that provide feedback rapidly, computer visualization of educational information, archiving of large amount of data with an easy access to database, automation of processes for computational, information and retrieval activity, processing of the results of experiments, the automation of management of training activities and monitoring of results.

Prospects for further research are to identity a set of conditions that provide the efficiency of virtual educational possibilities in training of future professionals in economic and finance areas.

\section{CONCLUSIONS}

The authors of this article reviewed scientific research on creation and use of virtual educational space, identified the main possibilities and justified the need for creation of virtual educational space that would enhance the efficiency of future economists training. 
The authors also analyzed information technology facilities that are used in the process of training of professionals in economic and finance areas. Based on the analysis, feasibility of information expert system use in the learning process to acquire the necessary knowledge, skills and methods of activities was justified.

In this study the authors developed and tested the system of economic competencies formation of future professionals in economic and finance areas.

While developing this system, the following tasks have been solved:

- criteria and indicators of economic competencies formation have been drawn up;

- three levels of economic competencies formation have been distinguished (low, average, high);

- the elements of virtual educational space (packaged applications, specialized automated systems, Internet resources) have been selected and implemented in the learning process of students' experimental group;

- information management of the system of economic competencies formation has been developed: diagnostic program complex to determine the competencies formation which includes test tasks with choice of responses and practical tasks with free response design;

- methodological recommendations for introducing the developed system have been drawn up.

The developed system was introduced in the learning process and its effectiveness was proved experimentally.

The authors hope that the results of the study and further suggestions will be used in the training of professionals in economic and finance areas to enhance the effectiveness of activities of higher education institutions.

\section{ACKNOWLEDGMENT}

The authors express his gratitude to anonymous reviewers for useful suggestions and recommendations, which allowed the authors to strengthen scientific reasoning, to extend bibliographic analysis and, in general, to improve the quality of the text.

\section{REFERENCES}

[1] D.V. Chernova, N.S. Sharafutdinova, I.I. Nurtdinov, Y.S. Valeeva, L.I. Kuzmina, "The transformation of the customer value of retail network services under digitalization," Digital Age: Chances, Challenges and Future "Lecture Notes in Networks and Systems" Cham, 2020, pp. 252260.

[2] D.V. Chernova, A.N. Skvortsova, E.V. Loginova, S.S. Sariev, A.Y. Polshinskaya, "Social networks as a tool of marketing communications in the commodity and service market," Advances in Intelligent Systems and Computing, vol. 726, 2019, pp. 943-949.

[3] Z.V. Arkhipova, V.A. Parkhomov, Information Technology in Economics: [training allowance], 2003.

[4] V.Y. Bykov, Models of Organizational Systems of Open Education. Monograph, 2008.

[5] M.G. Sergeeva, E.V Tabuyeva., E.P. Komarovskaya, L.B. Bakhtigulova, P.F. Kalashnikov, A.D. Galyuk, "Educational company": peculiarities of the technology's implementation at different educational levels when forming the economic competencies of future specialists," Espacios, vol. 39(12), 2018, p. 25.

[6] M.G. Sergeeva, M.S. Mohammad Anwar, T.G. Stanchuliak, N.N. Bedenko, T.Y. Tsibizova, "Organisational economic mechanism of managing the growth of higher education services quality," Espacios, vol. 39(21), 2018, p. 10.

[7] M.G. Sergeeva, N.L. Sokolova, I.S. Samokhin, "On the issue of the educational and educational components of continuing economic education," Scientific dialogue, vol. 7, 2018, pp. 31-345.

[8] S.I. Shuklin, The possibilities of virtual education and the conditions for their implementation in the training of future specialists : author. dis. for a job. scientist step. Cand. ped Sciences: special. 13.00.08 "Theory and methodology of vocational education", Kursk, 2010.

[9] V.A. Usov, The possibilities of virtual educational space in the organization of self-development of students at a university: autoref. dis. for a job. scientist step. Cand. ped Sciences: special. 13.00.01 "General pedagogy, the history of pedagogy and education", Sochi, 2006.

[10] R.V. Lubkov, The didactic potential of the virtual educational environment: autoref. dis. for a job. scientist step. Cand. ped Sciences: specialty 13.00.01 "General pedagogy, the history of pedagogy and education", Samara, 2007.

[11] R. Gurevich, M. Kademiya, "Information and Communication Technologies in Modern Vocational Education," Theory and methodology of vocational education, vol. 1, 2011.

[12] M.P. Lapchik, Computer science and information technology in the system of general and teacher education: Ist.-methodol. aspect,1999.

[13] A.Yu. Pylypchuk "Education Reformation and Informatization: basic problems and approaches to their solution," Information technology and training tools, vol. 1, 2008.

[14] M.G. Sergeeva, I.A. Pugachev, M.B. Budiltseva, I.Y. Varlamova, N.S. Novikova, N.V. Genina, "The importance of mathematical sciences in the development of future specialists' potential in socioeconomic researching," Espacios, vol. 39(21), 2018, p. 27.

[15] Yu.S. Ezrokh, "HR perspectives of Russian universities: Who will teach in the near future?," The Education and Science Journal, vol. 7(21), 2013, pp. 9-40.

[16] Yu.S. Ezrokh, "Game methodology for stimulating the motivation and success of educational activities of junior economists," Education and science, vol. 7(116), 2014, pp. 87-102.

[17] T.B. Poyasok, System of Application of Information Technologies in Professional Economists' Training in Higher Educational Institutions: dis. ... d. ped. sciences, 2009.

[18] L.V. Andrukhiv, The Formation of Future Economists' Ability to Work with Information: autoref. dis. for a job. scientist step. Cand. ped Sciences: specialty 13.00 .08 "Theory and methodology of vocational education", Astrakhan, 2008.

[19] N.T. Tverezovskaya, Theoretical and methodological bases of creation and use of educational expert systems in training of specialists of higher educational institutions: author's abstract. diss. for the sciences. degree of ped. Sciences: Special. 13.00.04 "Theory and Methods of Vocational Education", Kharkiv, 2003.

[20] N.T. Tverezovska, D.Y. Kasatkin, "Informational and educational learning environment: the history, classification and functions," Scientific notes of the Ternopil National Pedagogical University named after Volodymyr Hnatyuk. Series: Pedagogy, vol. 3, 2017, pp.190-196. 